\title{
MOVIMENTOS POPULARES E A QUESTÃO DA TERRA: A CONSTRUÇÃO DE UM DIREITO INSURGENTE
}

\section{POPULAR MOVEMENTS AND THE LAND ISSUE: THE CONSTRUCTION OF AN INSURGENT LAW}

\section{Luís Renato Vedovato ${ }^{1}$ Larissa Nunes ${ }^{2}$}

\section{Resumo}

O presente artigo tem como objetivo apontar a construção de um direito legítimo a partir das lutas da classe trabalhadora organizadas através dos movimentos populares, mais especificamente na questão da luta pela terra. Este direito legítimo é chamado "direito insurgente", de acordo com uma concepção traçada pelo jurista Miguel Baldez. Para tanto, foram realizadas pesquisas bibliográficas e entrevistas presenciais com Miguel Baldez. A fim de apontar e justificar esta construção jurídica, o modo capitalista de produção e o direito burguês são questionados ao longo do processo histórico dos últimos séculos, onde o pensamento crítico formulado por Marx e as revoluções constituem a base dos enfrentamentos realizados até hoje no contexto da luta de classes. A criação deste novo direito, insurgente, é então trazida de maneira concreta à realidade atual, justificada pelo caráter democrático, dialético e, portanto instituidor de direitos dos movimentos populares e pela necessidade de um direito que surja como expressão jurídica legítima das lutas populares, lançando bases para necessárias transformações sociais e jurídicas.

Palavras-chave: DIREITO INSURGENTE; MOVIMENTOS POPULARES; LUTA PELA TERRA; MORADIA; CLASSE TRABALHADORA.

\section{Abstract}

This paper aims to point out the construction of a legitimate law that emerges from the working class struggles, organized through popular movements, specifically in the conflicts over land

\footnotetext{
${ }^{1}$ Doutor em Direito Internacional pela Faculdade de Direito da Universidade de São Paulo. Professor MS3 da Unicamp. Professor do Programa de Mestrado da UNIMEP. Pesquisador associado do Projeto Fapesp Observatório das migrações em São Paulo. E-mail: Irvedovato@gmail.com

${ }^{2}$ Mestranda em Direito pela Universidade Metodista de Piracicaba. E-mail: larissarnunes@gmail.com
} 
rights. This legitimate law is called "insurgent law", a construction from the perspective of jurist Miguel Baldez. In order to achieve that, bibliographical researches and interviews with Miguel Baldez were carried out. To point out and justify this legal arrangement, the capitalist mode of production and the bourgeois law are questioned throughout the historical process of the last centuries, whereas the critical thinking formulated by Marx and the revolutions are the base for the conflicts that occur until now in the context of the class struggle. The creation of this new insurgent law is, then, brought to our current reality concretely, justified through the popular movements democratic and dialectical features, that are, therefore, founder of rights, and through the need of a law that rise as legitimate legal expression of the popular struggles, laying foundations to essential social and legal transformations.

Keywords: INSURGENT LAW; POPULAR MOVEMENTS; CONFLICTS OVER LAND; HOUSING; WORKING CLASS. 


\section{INTRODUÇÃO}

A proposta deste artigo é um resultado direto da práxis extensionista e comunicativa que se apresentou através do Núcleo de Assessoria Jurídica Universitária Popular (NAJUP), liderado pelo professor Miguel Baldez até o ano de 2012 na faculdade IBMEC-RJ. Através da experiência com o NAJUP e sua inerente criticidade, a ideia de um trabalho que ultrapassasse as linhas do dogmatismo jurídico, alcançando a realidade social dos conflitos relacionados à questão da terra - os movimentos populares - nasceu e se desenvolveu fundamentada na opressão diária que o direito posto (burguês) impõe e nas possíveis alternativas de enfrentamento a este direito, formuladas especialmente sob a ótica de Miguel Baldez.

O ponto de partida é a compreensão do processo histórico e social no qual o direito burguês se desenvolveu e se desenvolve, e em como este processo está diretamente ligado à luta de classes e à exclusão dos trabalhadores especialmente no que concerne à questão da moradia.

Nos grandes centros urbanos, estes enfrentamentos são aguçados e, mesmo com a aparente evolução trazida com os princípios constitucionais da Carta Magna de 1988, os conflitos continuam e os trabalhadores permanecem fragilizados ante a classe dominante.

Assim, primeiro será demonstrado através de uma pesquisa histórica, o surgimento e desenvolvimento do direito burguês no mundo e a reação a este direito, especialmente através da Revolução Russa e a consequente produção teórica/jurídica neste contexto. Em seguida, abordar-se-á o desenvolvimento do modo de produção capitalista que se deu no Brasil através de leis tipicamente burguesas, promovendo uma cerca jurídica ao redor da terra e excluindo a classe trabalhadora do acesso a este direito.

A reação a este intrincado conjunto de leis e seu caráter excluidor e classista também será discutida, em uma análise cronológica, passando pelos movimentos camponeses, ditadura militar e a redemocratização do país.

Além das pesquisas bibliográficas, neste trabalho também foi utilizada uma série de entrevistas com o professor Baldez, realizadas no Instituto de Estudos Críticos do Direito (IECD), com sede no Instituto dos Advogados Brasileiros (IAB) do Rio de Janeiro, a fim de enriquecer e trazer novas perspectivas do jurista acerca da construção, conceituação e perspectivas do direito insurgente.

Assim, a visão de Baldez permeia o desenvolvimento deste trabalho como um todo, e a construção histórica une-se à sua perspectiva digressiva e dialética a fim de demonstrar o 
surgimento de novos direitos concretizados através dos movimentos populares, abarcados pelo conceito de direito insurgente, concebido por Baldez.

\section{O PROCESSO HISTÓRICO DA FORMAÇÃO DO DIREITO BURGUÊS E SUAS CONSEQUÊNCIAS}

A construção de um direito insurgente a partir dos movimentos populares, como se quer demonstrar através deste trabalho, passa necessariamente por uma breve digressão histórica acerca da evolução do "direito dado", ou seja, do direito que se formou por meio de transformações sociais e suas respectivas ideologias ao longo dos anos. Como bem define Roberto Lyra Filho (1982, p. 08), a lei emanada do Estado está sempre ligada à classe dominante, já que o Estado é, usualmente, controlado por aqueles que estão à frente dos processos econômicos, enquanto proprietários dos meios de produção.

No Estado Absolutista o poder estava completamente concentrado nas mãos dos reis, soberanos supremos, através dos quais o direito era emanado, única e arbitrariamente, conforme suas vontades próprias e sem diálogo algum com o povo, impedindo o desenvolvimento individual e coletivo da sociedade, promovendo e conservando a ampla desigualdade entre os cidadãos.

Com tais características, a reação a este modelo de Estado veio com as ideias iluministas, que defendiam a liberdade e o tratamento igualitário aos cidadãos. Dentro deste período, as revoluções burguesas surgiram, sendo a mais significativa delas a Revolução Francesa (1789-1799). A lei, no lluminismo, devia ser baseada na razão, e, desta maneira, as revoluções burguesas trouxeram o direito natural moderno, longe do dogmatismo medieval, mas reconhecendo que há, naturalmente, na sociedade, um conjunto de valores e de direitos humanos legítimos e naturais, válidos em si mesmos por delineações éticas e morais, daí o lema da Revolução Francesa - liberdade, igualdade e fraternidade. Trata-se da derrocada do Estado Absolutista e o surgimento do Estado Burguês-Liberal.

Este processo de derrocada de um modelo de Estado através de revoluções é uma dinâmica que se repete ao longo da história, desde sempre, afinal, "a história de todas as sociedades até hoje existentes é a história das lutas de classes" (ENGELS; MARX, 2010, p.40). Os antagonismos de classes sempre existiram e sempre viveram em uma "guerra ininterrupta, ora franca, ora disfarçada; uma guerra que terminou sempre ou por uma transformação revolucionária da sociedade inteira, ou pela destruição das duas classes em conflito" (ENGELS; 
MARX, 2010, p.41). A burguesia foi, historicamente, revolucionária, já que, por onde passou e conquistou o poder, aniquilou as relações anteriormente estabelecidas. No entanto, apesar de ter levantado a bandeira da liberdade, da igualdade e da fraternidade como lema de suas revoluções, não chegou nem perto de abolir os antagonismos de classes, pelo contrário, simplificou tal processo para seu proveito próprio.

Assim, a partir da Revolução Francesa, percebe-se o nascimento, desenvolvimento e evolução de mecanismos elaborados pela burguesia a fim de garantir seu poder e domínio: a nova classe política da burguesia transfere ao Estado a regulação e a administração das relações da sociedade, reduzindo os conflitos a interesses individuais. A igualdade proposta pela burguesia se traduz na lei, mas se contradiz na prática, no concreto, reduzindo-se a uma igualdade ideológica.

A concretização da base fundamental do estado liberal-burguês, que é a separação entre o Estado e a sociedade civil, cabendo ao Estado apenas a manutenção pacífica das relações individuais entre os cidadãos, seria garantida através da norma jurídica, finalística e obrigatória, emanada de um estado "neutro". É através do Código de Napoleão, auge do positivismo, que esta concretização nasce e floresce como um instrumento de dominação e abstração, constituindo-se em um "acontecimento fundamental, que teve uma ampla repercussão e produziu uma profunda influência no desenvolvimento do pensamento jurídico moderno e contemporâneo." (BOBBIO, 2006, p.63).

Obviamente, tal neutralidade de Estado e da norma jurídica é abstrata, já que o Estado está sempre ligado diretamente à classe dominante, e, portanto, cumpre os objetivos e vontades desta, dividindo a sociedade em classes, onde a liberdade e a igualdade de todos aos bens "só poderá ser uma abstração e, portanto, uma ideologia jurídica" (CHAUÍ, 1986, p.20).

As consequências deste modelo de Estado, obviamente, repercutiram em todas as esferas, econômicas, sociais e políticas, gerando rupturas e crises, já que o individualismo exacerbava cada dia mais as desigualdades sociais e a classe dominante oprimia incessantemente a minoria proletária a fim de manter o sistema de produção capitalista e as relações de produção que este sistema necessita.

\section{O MANIFESTO COMUNISTA E A REVOLUÇÃO RUSSA}

Em meados do século XIX, na Europa, Marx e Engels publicam o Manifesto Comunista, que consistiu não somente na primeira grande manifestação teórica e ampla de denúncia do 
capital, mas também em uma convocação de forças para resistir os impiedosos efeitos deste sistema (BALDEZ, 1989, p.02). Na Europa, portanto, a crise do Estado Burguês já havia evoluído para um momento de organização e resistência dos trabalhadores a ponto de surgir uma proposta política alternativa, qual seja, o Manifesto Comunista, que lançava as bases para a luta pelo reconhecimento das liberdades e direitos do trabalhador.

A primeira experiência com o intuito de colocar em prática as ideias de Marx e Engels veio com a Revolução Russa, em 1917, com a construção do estado soviético. A Revolução Russa transferiu os meios de produção dos particulares para o Estado, de acordo com as medidas propostas no Manifesto Comunista ${ }^{3}$.

A transição de um estado burguês para um estado socialista não foi algo simples, especialmente no campo jurídico, o que gerou uma importante produção crítica do direito, principalmente entre os juristas soviéticos Stutchka e Pachukanis, que desenvolvem a teoria antinormativista como resposta ao direito burguês e sua relação com a nova sociedade, pósrevolução. As demandas concretas de reorganização política e jurídica e a necessidade de consolidar uma nova ordem, agora socialista, fizeram este período produzir um pensamento jurídico diferenciado e indispensável.

O direito, até o momento, era concebido no sentido burguês, e, portanto, fazia-se necessária uma nova definição, baseada em uma ruptura necessária para uma nova conceituação, trazida por Stutchka, com o Comissariado da Justiça, em 1919: “O Direito é um sistema (ordem) de relações sociais, que corresponde aos interesses da classe dominante e que, por isso é assegurado pelo seu poder organizado (o Estado)" (STUTCHKA, 2001, p.47). Para Pazello e Soares (2014, p. 487) esta definição é primorosa, já que

(...) observar o direito, não como uma categoria universal, mas como uma forma específica das relações sociais, significa visualizá-lo como uma forma histórica de mediação entre as relações de produção, troca e apropriação. Por sua vez, a sua vinculação com os interesses da classe dominante resulta numa ruptura ideológica com a ideia do direito enquanto uma expressão dos interesses públicos/universais para compreendê-lo como fruto de interesses contraditórios derivados de uma sociedade cindida em classes.

Tem-se também, não de menor importância, a teoria marxista do direito concebida por Pachukanis, em sua obra Teoria Geral do Direito e Marxismo, que parte das premissas iniciais de

\footnotetext{
${ }^{3}$ No segundo capítulo do Manifesto Comunista são listadas dez (10) medidas para a aplicação do comunismo na sociedade, como parte da primeira fase da revolução operária, indispensáveis como meio de transformação do modo de produção.
} 
Stutchka e vai um pouco além, discutindo mais detalhadamente sobre as relações sociais e a forma jurídica que elas adquirem em certas condições.

Pachukanis acreditava que o direito burguês e suas categorias não deveriam ser completamente aniquilados, pois, já que o direito é consequência das relações humanas em momentos específicos, a aniquilação do direito burguês significaria a aniquilação do direito em geral, pois não se levaria mais em conta o momento jurídico das relações humanas. Assim, ele constrói um raciocínio metódico no qual equipara o que Marx diz sobre as categorias econômicas às categorias jurídicas, já que mesmo aparentando uma universalidade, "elas exprimem um determinado aspecto da existência de um determinado sujeito histórico: a produção mercantil da sociedade burguesa" (PACHUKANIS, 1988, p. 35). Destarte, como Marx descreve o capital como uma relação social, o direito também corresponde a uma relação social específica, já que a regulamentação das relações sociais é revestida, historicamente, de um caráter jurídico e, assim, o papel do jurista teria uma função social prática (PACHUKANIS, 1988, p. 42).

Desta maneira, observamos, em ambos os juristas soviéticos, uma teoria do direito que nega o universalismo abstrato e é "capaz de compreender a mediação jurídica enquanto uma forma social engendrada na rotação desmedida do capital na realização da mais-valia" (PAZELLO; SOARES, 2014, p. 494). A concepção de Stutchka e Pachukanis é antinormativista, o que não significa a negação do direito, a anarquia, mas a observação atenta dos limites da forma jurídica com relação à concepção burguesa na construção e organização de um novo direito, capaz de superar a normatividade burguesa abstrata e alienada.

\section{A INTRODUÇÃO DO DIREITO BURGUÊS NO BRASIL}

Enquanto na Europa o Manifesto Comunista já havia sido publicado, a Revolução Russa já havia iniciado e a classe operária já começava a se organizar de maneira generalizada com algumas conquistas fundamentais e históricas, no Brasil "ainda estavam sendo lançados os fundamentos para a passagem do capitalismo mercantilista ao capitalismo industrial" (informação verbal $\left.{ }^{4}\right)$. A distância do processo histórico entre a Europa e o Brasil não é um fato isolado e insignificante, afinal, "no Brasil, o atraso é um instrumento de poder" (MARTINS, 1994, p.13).

\footnotetext{
${ }^{4}$ Entrevista concedida por Miguel Lanzellotti Baldez no Instituto de Estudos Críticos do Direito, no Rio de Janeiro, em outubro de 2015.
} 
A consolidação da passagem do capitalismo mercantilista ao capitalismo industrial, no Brasil, se consolida no campo institucional do legalismo (MARTINS, 1994, p. 14), especialmente a partir do ano de 1850, ponto de partida de uma ampla produção jurídica articulada como fundamento para estas transformações.

Desta maneira, no Brasil, o movimento de cercamento jurídico do Estado burguês estava apenas começando, mas de uma maneira direta e incisiva: na terra, na noção de propriedade. Ora, não é mera coincidência o fato de a produção jurídica intensa no Brasil começar em 1850 com a Lei de Terras (Lei n. 601/1850) que no seu Art. 10 estabelece que a aquisição de terras seria possível somente através de compra e venda, afinal, a propriedade privada e o contratualismo são fundamentos essenciais da ordem burguesa e da manutenção do modo de produção capitalista.

A malha jurídica burguesa no Brasil continuou a crescer e se desenvolver, e pode-se dizer que o auge deste processo se deu com a promulgação, em 1916, do Código Civil Brasileiro, fruto de influência direta do Código de Napoleão, concretizando, no Brasil, os fundamentos do Estado burguês.

\section{A ESCRAVIZAÇÃO DA TERRA NO BRASIL}

O processo de acumulação de terras no Brasil gerou movimentos populares ligados a esta questão como consequência direta dos mecanismos envolvidos no que pode ser chamado de "escravização da terra" (BALDEZ, 1989, p.31).

A origem do latifúndio, no Brasil Colônia, pode ser considerada o ponto de partida para o delineamento das características dominantes da propriedade no campo até os dias de hoje. A origem deste latifúndio está, sem sombra de dúvidas, no sistema de outorga de sesmarias (informação verbal ${ }^{5}$ ) que eram distribuídas de acordo com a vontade do capitão-mor que representasse, em cada localidade, a Coroa. O "colono", o morador de tais terras, só respondia pelo não cultivo, o que era uma "cláusula essencial na restrição do domínio, ao soberano e à sua justiça" (FAORO, 2001, p.163).

Posteriormente, $\mathrm{o}$ ato de conceder sesmarias passou a estipular que estas seriam concedidas "para quem residisse nas povoações e em tamanho não tão grande que não pudesse o beneficiário mesmo aproveitar" (MARÉS, 2003, p.60). No entanto, não foi isso que

\footnotetext{
${ }^{5}$ Entrevista concedida por Miguel Lanzellotti Baldez no Instituto de Estudos Críticos do Direito, no Rio de Janeiro, em setembro de 2015.
} 
aconteceu, e as sesmarias foram concedidas em grandes extensões, sem respeitar as terras indígenas nem a capacidade imediata do concessionário.

A ocupação territorial livre era, portanto, vedada, com o objetivo claro de expandir o capital comercial europeu, e não colonizar o país com um ocasional excesso de população. No entanto, o Brasil apresentava excesso de terra e falta de mão de obra, e, por ser um sistema essencialmente baseado na concessão de terras em Portugal, ficava claro que tal sistema, importado para o Brasil, tendo em vista as grandes diferenças entre os países, seria problemático. Desta maneira, o limite imposto às concessões sesmariais foi muitas vezes desrespeitado, o que acabou fazendo com que o sistema sesmarial se tornasse a origem da formação de latifúndios, em uma mentalidade que persiste até hoje.

A contradição no uso das sesmarias em Portugal e no Brasil é bem descrita através da análise de Carlos Frederico Marés (2003, p.62):

[...] as sesmarias nasceram em Portugal para que o Poder Público dispusesse das terras não trabalhadas, mesmo que de propriedade alheia, para oferecer a quem realmente a quisesse trabalhar, na medida de seu trabalho; enquanto no Brasil a mesma concessão é negada a quem quisesse trabalhar e produzir por sua conta e entregue a quem tivesse 0 poder de explorar o trabalho alheio adquirido à força, compulsoriamente, seja como escravo ou trabalhador livre, que tinham que aceitar as condições independente de sua vontade [...]

Nesta época, a produção era baseada no regime escravagista, onde o escravo era, em suas características essenciais: “a) propriedade privada de outro indivíduo; b) trabalhava sob coação física extra-econômica; c) todo o produto do seu trabalho pertencia ao senhor" (GORENDER, 1990, p.87). Desta maneira, através da escravidão, o capital definia e organizava o processo de trabalho, mas de uma maneira um pouco diferente da usual, já que no regime escravagista, segundo José de Souza Martins (2010, p. 31):

[...] as relações de produção entre o senhor e o escravo produziam, de um lado, um capitalista muito específico, para quem a sujeição do trabalho ao capital não estava principalmente baseada no monopólio dos meios de produção, mas no monopólio do próprio trabalho, transfigurado em renda capitalizada. [...] De outro lado, essas relações, sendo desiguais - não sendo fator, mas condição do capital -, produziam um trabalhador igualmente específico, sua gênese não era mediada por uma relação de troca de equivalentes [...], mas sim pela desigualdade que derivava diretamente da sua condição tributária de renda capitalizada[...]. A escravidão definia-se, portanto, como uma modalidade de exploração da força de trabalho baseada direta e previamente na sujeição do trabalho, através do trabalhador-mercadoria, ao capital comercial. 
O escravo, portanto, era a própria renda capitalizada, e, desta maneira, os donos da terra não precisavam se preocupar com a proteção desta, afinal, a capitalização de sua renda estava configurada nos escravos.

Porém, no ano de 1822, através de uma resolução da Mesa do Desembargo do Paço, foi determinada a suspensão do sistema de sesmarias. Novas concessões estavam proibidas, mas as que tivessem sido concedidas até aquele momento, de acordo com as leis, lavradas, demarcadas e confirmadas, seriam consideradas legítimas. Depois disto, até o ano de 1850, o único modo de aquisição da propriedade ficou sendo o das ocupações, que eram essencialmente individuais e admitidas como um meio próprio e legítimo de aquisição de terra. O país ficou quase 30 anos sem nenhuma legislação sobre a propriedade rural.

O sistema sesmarial estava suspenso, mas o problema dos latifúndios não, afinal, as ocupações não mudaram o caráter de domínio da propriedade que já estava delineado no Brasil, como aponta Ruy Cirne Lima (1954, p. 54):

Depois de 1822, sobretudo - data da abolição das sesmarias - as posses passam a abranger fazendas inteiras e léguas a fio. Se as sesmarias formavam verdadeiros latifúndios [...] mais extensas ainda eram as posses, cujas divisas os posseiros marcavam de olho nas vertentes, ou onde bem Ihes aprazia. A tendência para a grande propriedade estava já definitivamente arraigada na psicologia da nossa gente.

Posteriormente, a partir de 1850, a compreensão do processo de acumulação capitalista se delineia e se revela através de um "surto de leis e regulamentos que viriam a ser baixados para envolver e patrimonializar, no interesse das camadas (ou castas) privilegiadas, as terras antes da Coroa" (BALDEZ, 1989, p.13). Tal surto inicia-se com a Lei Eusébio de Queirós, que extinguiu o tráfico negreiro no Brasil e a Lei no 601, a primeira Lei de Terras.

Cabe ressaltar que, apesar de tratarem de assuntos completamente distintos, estas duas leis estão intimamente ligadas, já que a terra vira objeto de preocupação do jurista apenas quando a figura do trabalhador livre surge. A (re)definição do trabalhador, que deixa de ser objeto direto da dominação e passa a ser um sujeito capaz de participar do mercado de trabalho - ou de qualquer outro mercado, teoricamente - faz com que o acesso natural à terra seja fechado para ele (BALDEZ, 2002, p. 98). Era, assim, indispensável uma complexa elaboração jurídica construída a fim de servir os interesses do capital, disponibilizando amplamente a submissão da força de trabalho.

Desta maneira, enquanto o regime escravagista durou, o investimento na mão-de-obra escrava tinha mais valor que o investimento na terra, dando-se como garantia o próprio negro, e não a terra. Mas, com o fim da escravidão, a terra passou a ter expressão econômica e foi 
monopolizada pelo latifúndio, sendo protegida primeiramente pela Lei no 601 e depois por outras leis de proteção à propriedade, como a Lei Hipotecária no 1237, de 24 de setembro de 1864 e o Decreto № 169 A, de 19 de janeiro de 1890, estabelecendo, assim, uma forte cerca jurídica em torno da terra.

A Lei de Terras consagrou o que antes não existia: a terra como capital, como riqueza capitalizada e, assim, no modo de produção capitalista, para que se tenha acesso a esta riqueza, é necessário trabalhar e poupar, sujeitando o trabalhador, agora "livre", a uma exploração contínua de sua força de trabalho na esperança de alcançar o seu pedaço de riqueza, um pedaço de terra, justamente o que lhe foi e é negado até os dias de hoje.

A Lei no 601 e a Lei Euzébio de Queirós são, portanto, diretamente ligadas e articuladas, onde, de um lado liberta-se o negro, mas sem incluí-lo na sociedade e, de outro, "consagravase, para garantir a destinação do homem ao mercado de trabalho, a escravização da terra" (BALDEZ, 1998, p. 14), requisito fundamental para o modo de produção capitalista e suas consequentes exclusões e opressões à classe trabalhadora.

\section{OS MOVIMENTOS CAMPONESES, A REFORMA AGRÁRIA E A DITADURA MILITAR}

Com o fim da escravidão, as condições de existência dos camponeses foram redefinidas, já que a interdição da propriedade os atingiu fortemente. Na análise de José de Souza Martins (2010, p. 279), os camponeses constituíam um grupo excluído do pacto político, esquecido, inferior.

O sistema colonial de sesmarias permitia ao fazendeiro que sua posse fosse legitimada através do título sesmarial, no entanto, o mesmo não ocorria com o camponês, já que "seus direitos se efetivavam em nome do fazendeiro" (MARTINS, 1983, p.35). Tratava-se de um sistema completamente diferenciado daquele estabelecido na sociedade feudal (FAORO, 2001, p. 42) e do regime escravagista, já que, aqui, o camponês vivia e trabalhava nas terras de algum fazendeiro, sendo um mero agregado, excluído da dinâmica capitalista daquele período, sem perspectiva de obter sequer um pedaço de terra para si, senão através de lutas. Assim, nos primeiros anos da República, as lutas camponesas se iniciam, sendo de importante lembrança a maior guerra popular da história contemporânea do Brasil, a Guerra do Contestado (19121916), no sul do país, e a Guerra dos Canudos (1896-1897), nos sertões da Bahia.

Iniciava-se aqui uma verdadeira resistência de classe, não sendo à toa a ocorrência de formas parecidas de resistência ao longo do território do país. Mesmo tendo seus motivos 
registrados historicamente de maneira conflitante, tais confrontos possuíam, em sua essência, os mesmos critérios de contestação da ordem social imposta pelo capitalismo.

Cabe destacar, neste período, a fundação do Partido Comunista Brasileiro em 1922 e o surgimento do Bloco Operário e Camponês, a fim de estabelecer uma aliança entre os camponeses e os operários, o campo e a cidade, respectivamente. De acordo com Dainis Karepovs (2006, p. 77), "tal alteração teve como intenção deixar manifesta a disposição dos comunistas de buscar expandir sua atuação também em direção aos trabalhadores do campo".

No entanto, somente na década de 50 tal visão foi de fato concretizada através da criação das Ligas Camponesas, que modificou por completo a manifestação camponesa, já que as Ligas Camponesas e os Sindicatos constituir-se-iam em formas mais importantes e relevantes da luta política no campo.

Iniciava-se uma nova fase de movimentos camponeses, que culminou com o episódio dos camponeses de Governador Valadares, que reivindicavam uma distribuição de terras da Fazenda Federal, irritando fazendeiros, que se organizaram com o objetivo de impedir a execução do plano de reforma agrária em uma fazenda que já era de propriedade do governo federal. Ocorre que a entrega destas terras estava prevista para o dia 30/03/1964 e, no dia seguinte, houve o golpe de Estado que derrubou o governo Goulart e implantou a ditadura militar. O que parecia um evento isolado foi, na realidade, o "estopim preparado pela CIA para o golpe, segundo os documentos do arquivo do presidente Lyndon Johnson" (MARTINS, 1983, p.70).

Trata-se, portanto, de ligação clara entre a luta tão necessária pela reforma agrária e a consequente resistência do capital através do Golpe de Estado. As lutas "cresceram e apareceram", e a reação da ordem social capitalista contra a possibilidade da reforma agrária foi rápida e incisiva. A Ditadura Militar, agora instalada, assume e incorpora no Estatuto da Terra todas as bandeiras do trabalhador na luta pela reforma agrária, mas não para realizá-las, já que este Estatuto proveu o tratamento jurídico adequado à questão agrária ao criar mecanismos relevantes como o rito sumaríssimo e a indenizabilidade em títulos de dívida pública e prazo longo, porém, transferiu para o Exército a "prevenção" de possíveis enfrentamentos. Era uma posição esquizofrênica propositada: a fim de remover os eventuais conflitos no campo, tratava de maneira correta o processo de reforma agrária através da legislação, mas impedia duramente a realização desta na prática.

No entanto, as lutas no campo não cessaram, apesar de a violência contra os trabalhadores aumentar a cada dia. Mesmo contidos pelo duplo controle - a lei "congelada" e a 
repressão do Exército - o trabalhador no campo cresceu na prática concreta das ocupações coletivas (BALDEZ, 1998, p.16). Este modo de ocupação foi uma novidade trazida pelo movimento popular, já que o caráter das ocupações nos tempos coloniais era essencialmente burguês, individualista, e as ocupações coletivas rompem com esta concepção, negando o contratualismo e constituindo um novo modo de aquisição da terra através da subjetivação coletiva, uma inovação puramente popular.

É de importante anotação o fato de que a luta contra o regime militar causava efeitos diferenciados na cidade e no campo, pois, de um lado parecia que somente no campo do Direito as garantias e liberdades fundamentais seriam alcançadas, através da redemocratização e reconstitucionalização do país. Por outro lado, especialmente no movimento pela reforma agrária, a consciência era a de que as elaborações jurídicas não ajudariam a alcançar o que se desejava, já que o Estado em si era uma elaboração burguesa e, como tal, jamais estenderia seus interesses à classe trabalhadora.

A noção de que as lutas seriam concretizadas através de instrumentos jurídicos trazidos pela redemocratização do país prevaleceu e a razão para tanto é descrita por Baldez (informação verbal ${ }^{6}$ ):

enquanto nas cidades o controle da classe trabalhadora se fez através do juridicismo individualizante e atomizador das lutas, no campo a repressão preservou os métodos herdados do escravagismo, mitigado pela ideologia do compadrio. Aconteceu, por isso, que as lideranças urbanas ficaram, em sua ótica mais imediata, absorvidas pela ideologia jurídica burguesa, e, por isso, acabaram desviadas, muitas vezes por opção tática, para a arena do legalismo, e esgotando-se, embora nem sempre na procura de novos e mais eficientes direitos, alguns até alcançados, mas cuja execução dependeria do poder, que nunca os oprimidos tiveram.

Foi exatamente este processo que influenciou, prevaleceu e motivou o movimento para a redemocratização da nação e a abertura para a reconstitucionalização do país através da campanha pelas eleições diretas com grandes mobilizações populares.

\section{A JURIDIFICAÇÃO DA AÇÃO POLÍTICA DA CLASSE TRABALHADORA E A QUESTÃO DA MORADIA}

Ao final da década de 70, a maioria do povo brasileiro- a classe trabalhadoraencontrava-se em uma situação complicada, decorrente de um processo que vinha desde a

\footnotetext{
${ }^{6}$ Entrevista concedida por Miguel Lanzellotti Baldez no Instituto de Estudos Críticos do Direito, no Rio de Janeiro, em agosto de 2015.
} 
época dos latifúndios: o trabalhador do campo sendo empurrado para as cidades, especialmente com o advento da ditadura militar. Os conflitos concretos da questão agrária e da questão urbana vinham se agravando até o limite e desta maneira, outros movimentos, novas lutas operárias e rurais, surgiram e se corporificaram em um sindicalismo mais avançado, tendo como principal característica a combatividade.

Estas lutas fizeram crescer também movimentos populares urbanos pela mobilidade urbana, saúde e, principalmente, pela moradia, já que, como destaca Engels (2015, p. 71), a escassez de moradia é um produto necessário na sociedade burguesa.

Portanto, deve-se frisar a importância de tais movimentos neste contexto de rompimento do regime autoritário, além da campanha nacional pelas eleições diretas, parte essencial do caminho para a redemocratização do País.

Através da instalação da Assembleia Constituinte, o espaço para a participação organizada dos movimentos populares foi aberto no processo de elaboração da Constituição através das emendas populares, a fim de discutir e elaborar uma proposta de reforma urbana. Neste cenário era preciso pacificar lutas e frustrações através do estabelecimento de regras e normas de convivência, a fim de compensar as perdas e tentar conter as lutas através de limites ideológicos de um ordenamento social, ou seja, através de uma juridificação da ação política (informação verbal ${ }^{7}$ ). As emendas populares nada mais eram que um dispositivo instituidor da participação popular, que cumpriu perfeitamente o papel de juridificar as lutas sindicais e populares no texto constitucional.

A luta política do povo foi, portanto, transformada em luta jurídica através das emendas populares, em um processo de separação formal entre o direito e o político, uma "individualização e atomização da realidade social operada pelo Direito" (SANTOS, 1982, p.26), mecanismo próprio da ideologia burguesa, já que "toda luta de classes é uma luta política" (ENGELS; MARX, 2010, p.48), e, portanto, deve ser esvaziada deste caráter e envolvida, contida e moldada no Direito concebido historicamente pelas classes dominantes.

Não se quer, aqui, desprezar tal espaço conquistado no processo de avanço democrático em que se encontrava o País. A proposta de reforma urbana discutida no âmbito das emendas populares trazia pontos e mecanismos fundamentais, além de princípios norteadores da questão democrática da cidade.

\footnotetext{
${ }^{7}$ Entrevista concedida por Miguel Lanzellotti Baldez no Instituto de Estudos Críticos do Direito, no Rio de Janeiro, em outubro de 2015.
} 
Todavia, esta questão democrática da cidade esbarra na coexistência de duas cidades: a cidade do trabalhador e a cidade produzida pelo capital. Fica claro que a classe trabalhadora vêse banida e mantida distante, pois o acesso à economia de mercado e, principalmente, o imobiliário, é inatingível pelo trabalhador, já que, nas palavras de Engels (2015, p. 40),

O resultado é que os trabalhadores são empurrados do centro das cidades para a periferia, as moradias dos trabalhadores e, de modo geral, as moradias menores se tornam raras e caras e muitas vezes nem podem ser adquiridas, porque nessas condições a indústria da construção civil, para a qual as moradias mais caras representam um campo de especulação muito mais atrativo, apenas excepcionalmente construirá moradias para trabalhadores.

Este confronto entre as duas cidades foi discutido amplamente durante o processo constituinte, passando pelo âmbito federal, estadual e municipal. Infelizmente, a promulgação da Constituição Federal veio para indicar claramente a composição de um sistema comprometido em suas bases com os interesses do capital através, principalmente, do tratamento dado ao direito de propriedade, fundamentado em características de absolutismo, exclusividade e perpetuidade.

Na visão de Baldez (1991, p. 10), a Constituição é apenas um elemento dentro do processo histórico, uma fase da luta de classes no processo institucional, e, desta maneira, a transformação da sociedade não deve limitar-se à Carta Magna pelo simples fato de que, no caso, a reforma agrária aparentemente havia se tornado inviável no texto constitucional.

A classe trabalhadora organizou-se neste momento histórico do País com o objetivo de concretizar sua ação política em busca de seus direitos, porém, o resultado foi a abstração jurídica de tal luta, onde o povo continua, até os dias de hoje, sem voz, especialmente no tocante à questão da terra. O monopólio da terra, sob o efeito da juridificação das lutas políticas da classe trabalhadora, continuou garantido às classes dominantes.

\section{AS OCUPAÇÕES COLETIVAS E OS MOVIMENTOS POPULARES}

Como visto, a questão da reforma agrária foi "congelada" no texto constitucional, em uma tentativa de juridificação do movimento político pela terra que, graças ao Movimento dos Trabalhadores Rurais sem Terra (MST), não foi bem sucedida. O MST agiu independente da cerca jurídica da terra, em favor das lutas concretas pela conquista e democratização desta, já que na questão da reforma agrária, a democratização não havia sido alcançada na Constituição. 
A luta, na democracia, não só é considerada legítima, mas é estimulada, afinal, os direitos dos cidadãos vão muito além da mera regulamentação jurídica formal, pois estes "são sujeitos de direitos e onde não existam tais direitos, nem estejam garantidos, tem-se o direito de lutar por eles, exigi-los. Este é o cerne da democracia." (CHAUÍ, 2002, p.334).

Assim é criado, através do MST, um importante mecanismo de apossamento de áreas abandonadas: as ocupações coletivas, um novo modo de aquisição da posse (informação verbal $\left.^{8}\right)$. Esta ação do MST veio justamente para demonstrar que o cercamento jurídico da terra não poderia prevalecer, visto que a ação política dos trabalhadores não resultou em uma concretização democrática na Constituição com relação à reforma agrária, e, portanto, as lutas deveriam continuar.

O MST, portanto, ampliou de maneira adequada e justa o conceito de terra improdutiva, utilizando a posse como um instrumento de correção da propriedade injusta, ressaltando a contradição entre o que é dito propriedade privada e a função social constitucional que esta deveria ter.

É importante distinguir, desde já, os movimentos sociais dos movimentos populares, como quer Baldez (informação verbal ${ }^{9}$ ). Tal distinção visa considerar de maneira individualizada o conteúdo como objeto de cada um deles. Os movimentos sociais são aqueles compatíveis ou suportáveis pelo sistema político atual, como os movimentos pela saúde, educação, direitos das mulheres, dos negros, direitos homoafetivos, etc. Já os movimentos populares são aqueles estratégicos que o sistema não admite: os movimentos sindicais (de trabalhadores) e os relativos à posse e à propriedade da terra, no campo e na cidade, pela produção no campo e nas cidades pela moradia.

O papel dos movimentos populares, na visão de Baldez (2013, p. 204), é único e revolucionário:

O movimento popular é o não-sujeito, o coletivo político e transformador: o sinal mais claro do advento de uma nova sociedade solidária e socialista, e, no percurso de suas conquistas, o caminho das lutas específicas que o caracterizam e personalizam. Nesse percurso, vão elaborando instâncias, institucionalizadas ou não, de vital importância para os subalternizados, nos embates de cada hora com a classe dominante e as elites dirigentes.

\footnotetext{
${ }^{8}$ Entrevista concedida por Miguel Lanzellotti Baldez no Instituto de Estudos Críticos do Direito, no Rio de Janeiro, em outubro de 2015.

${ }^{9}$ Entrevista concedida por Miguel Lanzellotti Baldez no Instituto de Estudos Críticos do Direito, no Rio de Janeiro, em agosto de 2015.
} 
A luta concreta do MST e de trabalhadores rurais traduz a essencialidade da participação popular na construção de uma sociedade de fato democrática em suas políticas públicas, já que "a reforma agrária não é um simples mecanismo ligado ao interesse residual de trabalhadores sem terra, mas uma ação coletiva de libertação que exige de toda a sociedade mais do que apoio: integração" (BALDEZ, 1986, p. 26).

\section{O DIREITO INSURGENTE DAS LUTAS CONCRETAS}

Os movimentos populares, como já definidos, são aqueles contra a ordem, contra o sistema instituído, e, portanto, revestidos de caráter revolucionário, como bem define Marilena Chauí (1986, p. 25):

A revolução é a contestação da cultura dominante de "fora" dela [...] Sob essa perspectiva, suponho que alguns movimentos sociais e populares podem ser considerados revolucionários [...] quando reivindicam direitos novos que criam sujeitos sociais e políticos novos, num contrapoder social que questiona a heteronomia do direito enquanto produto do poder estatal.

Para Baldez (informação verbal ${ }^{10}$ ), o MST, através das ocupações coletivas, cria uma subjetivação coletiva ao negar o conceito burguês de propriedade privada, e, ao fazer isto, propõe um novo conceito de propriedade a partir da reconceituação da posse. Desta maneira, a ocupação coletiva é dotada de um caráter instituinte de novos direitos através da relação dialética que a compõe.

Infelizmente, a sociedade está estruturada de tal maneira que os direitos ditos universais do homem e do cidadão não podem existir de maneira concreta, ou seja, a democracia que se apresenta é apenas formal, não material. É por esta razão que, de acordo com Marilena Chauí (2002, p. 334) uma sociedade é democrática quando institui direitos, ou seja, a mera declaração do direito à igualdade não torna instantânea a existência dos iguais, mas possibilita a construção da igualdade através das necessidades e demandas dos sujeitos sociais, instituindo assim, de fato, novos direitos.

Porém, cabe aqui o questionamento acerca da natureza destes direitos que nascem das ações destes movimentos e quais seriam as consequências sociais e jurídicas trazidas por eles. É neste contexto que Baldez cria, juntamente com Miguel Pressburger, o conceito de Direito Insurgente.

\footnotetext{
${ }^{10}$ Entrevista concedida por Miguel Lanzellotti Baldez no Instituto de Estudos Críticos do Direito, no Rio de Janeiro, em novembro de 2015.
} 
Cabe aqui, antes de adentrar o conceito de direito insurgente de maneira específica, diferenciar as expressões "direito alternativo", "uso alternativo do direito", "direito insurgente" e "direito achado na rua". Como bem pontua Baldez (2013, p. 195), o "uso alternativo do direito" e o "direito alternativo" não são exatamente a mesma coisa, pois

Enquanto a expressão direito alternativo é reservada, como conceito, para as práticas jurídicas desenvolvidas através de discussões internas nas comunidades oprimidas, marginalizadas pelo direito oficial (como, por exemplo, favelas e loteamentos periféricos), uso alternativo do direito exprime a prática de funcionários progressistas do poder judiciário, principalmente magistrados, no trato das demandas.

De acordo com análise de Roberto Lyra Filho (1982, p. 55), o uso alternativo do direito positivo e estatal consiste em examinar as antíteses do direito positivo e estatal em prol dos oprimidos. Porém, como observado pelo próprio Lyra Filho na continuidade de seu texto e também por Baldez e Pressburger, a designação mais adequada para a dinâmica dialética resultante dos movimentos populares não seria a de um direito alternativo ou uso alternativo do direito, já que estes apenas supririam as lacunas positivas do Direito. Era necessário um direito de reversão ao direito dado, e não uma alternativa ao direito dado (informação verbal ${ }^{11}$ ).

Trata-se de um direito contra a ordem, por isso dotado de caráter essencialmente insurgente, fundamentalmente baseado na ruptura com a "ideologia classista de que o direito é o mesmo para todas as épocas e lugares, devendo ser aplicado indistintamente, sem levar em conta as grandes diferenças sociais, econômicas e culturais de classe." (BALDEZ, 2013, p.196)

Assim, Baldez (2013, p. 195) define o direito insurgente como um

conceito mais amplo e subordinante das ações alternativas, de uso (alternativo) ou propriamente dita (direito alternativo), conceito que não pode confinar-se nas especulações e no ensaismo do mundo acadêmico, cuja importância não deve, porém, ser minimizada, este conceito de direito insurgente encontra sua razão de ser nas lutas concretas da classe trabalhadora e na crítica permanente às estruturas da sociedade capitalista.

Diferencia-se, portanto, do "direito achado na rua", que é uma expressão criada por Roberto Lyra Filho no campo acadêmico de um curso e linha de pesquisa organizados na Universidade de Brasília com o objetivo de capacitar assessorias jurídicas de movimentos populares e buscar "ser a expressão do processo que reconhece na atuação jurídica dos novos sujeitos coletivos e das experiências por eles desenvolvidas de criação de direito" (SOUSA JUNIOR, 2008, p.193).

\footnotetext{
${ }^{11}$ Entrevista concedida por Miguel Lanzellotti Baldez no Instituto de Estudos Críticos do Direito, no Rio de Janeiro, em outubro de 2015.
} 
Desta maneira, o direito achado na rua situa-se num campo mais acadêmico, teórico, enquanto que o direito insurgente nasce e cresce no seio das lutas populares concretas.

Ainda na visão de Baldez (2013, p. 201), a ação e as consequências deste direito insurgente sempre acompanharam os movimentos populares no Brasil, refletindo no ordenamento jurídico do país, especificamente na integração de direitos fundamentais na estrutura formal da Constituição, como a função social da propriedade, direitos sociais coletivos e direitos sociais específicos, como o direito à saúde, educação, trabalho, lazer, etc.

As consequências do direito insurgente também podem ser percebidas no contexto do Poder Judiciário, onde Baldez (2013, p. 203) novamente aponta para a importância das ocupações coletivas, já que o exemplo mais comum desta interação engessada do Judiciário repousa nas ações propostas contra as ocupações coletivas no país como um todo. Em sua brilhante análise, nenhum juiz aceitaria o fetiche da neutralidade da lei, em tais casos, se estivesse de fato comprometido com as lutas da classe trabalhadora, decretando o despejo dos ocupantes e negando a luta do trabalhador sem terra para sobreviver e produzir. Um juiz comprometido agiria no sentido de um direito insurgente, de um diálogo dialético entre a realidade social e o direito dado.

O direito insurgente é, portanto, aquele decorrente do trabalho, do trabalhador. Através da ocupação coletiva, que é, como já apontado, um ato político-jurídico, é criado um modo coletivo de aquisição de terra, um novo direito, um direito insurgente, que rompe com a ordem dada, especificamente com o vínculo jurídico da propriedade. Através da prática coletiva do trabalhador, este direito novo, "nascido das contradições sociais e cuja consolidação contra a ordem burguesa irá ocorrer no concreto, ultrapassando ou contrariando aquela ordem, romperá com a asfixia do direito positivo burguês" (BALDEZ, 1990, p.118).

\section{CONSIDERAÇÕES FINAIS}

O processo histórico que envolveu o estabelecimento do modo de produção capitalista foi construído através da indispensável malha jurídica de caráter essencialmente burguês engendrada ao redor do mundo. No Brasil, este sistema se formou por meio da escravização da terra, excluindo o acesso do trabalhador a esta e perpetuando uma cerca jurídica e física deste bem tão essencial e intrínseco ao ser humano. 
As reações a este sistema e suas consequências foram e são concretizadas através dos movimentos populares, fundamentalmente democráticos e, portanto, dialéticos e legítimos, capazes de instituir novos direitos através de suas ações.

A instituição de novos direitos não é apenas uma consequência destes movimentos, mas traduz-se em uma necessidade atual, de um direito que atenda às necessidades da classe trabalhadora, excluída e oprimida pela classe dominante. No contexto dos conflitos sociais hoje existentes, um direito que vislumbre a realidade social é requisito essencial e indispensável para uma sociedade materialmente democrática.

O conceito de direito insurgente abarca estas concepções e suas ramificações, já que se trata de um direito que insurge contra a ordem estabelecida, nasce e se renova através da prática política da classe trabalhadora, possuindo, portanto, dinâmica dialética, capaz de contribuir para importantes transformações sociais, não se limitando, desta maneira, ao campo acadêmico, mas lançando as bases para a construção de uma sociedade justa, igualitária, e democrática.

\section{REFERÊNCIAS BIBLIOGRÁFICAS}

BALDEZ, Miguel Lanzellotti. A Constituição e a Reforma Urbana. 1ạed. Petrópolis: CDDH, 1989.

A Terra no Campo: A Questão Agrária. In: Introdução ao Direito Agrário. Curso de Extensão Universitária, Série O Direito Achado na Rua. v.3. Brasília: Editora UnB, pp. 97-105, 2002.

Anotações sobre o Direito Insurgente. Disponível em: <http://www.forumjustica.com.br/wp-content/uploads/2013/02/Direito-InsurgenteBaldez.pdf.> Acesso em: 12 mar. 2015.

Direito Insurgente: um roteiro de estudo. [julho a novembro, 2015]. Instituto de Estudos Críticos do Direito. Rio de Janeiro. Entrevistas concedidas a Larissa dos Reis Nunes no Instituto dos Advogados Brasileiros

Notas sobre a Democratização do Processo. Revista de Direito da Defensoria Pública, Rio de Janeiro, v. 10, n. 12, p. 13-23, 1998.

Sobre a Reforma Urbana. 1ạed. Petrópolis: CDDH, 1991.

Sobre o Papel do Direito na Sociedade Capitalista. Ocupações Coletivas: Direito Insurgente. Revista de Direito da Defensoria Pública, Rio de Janeiro, n. 3, p. 104-126, set. 1990. 
Solo Urbano; Reforma, Propostas para a Constituinte. Revista de Direito da Procuradoria Geral, Rio de Janeiro, no 38, p.104-120. 1986.

BOBBIO, Norberto. O Positivismo Jurídico: Lições de Filosofia do Direito. 1aed. São Paulo: Ícone, 2006.

BRASIL. Constituição Federal (1988). Constituição da República Federativa do Brasil: promulgada em 05 de outubro de 1988. Disponível em: <http://www.planalto.gov.br/ccivil_03/Constituicao/Constituicao.htm>. Acesso em: 12 abr. 2015.

Lei ํo 601, de 18 de setembro de 1850. Dispõe sobre as terras devolutas do império. Disponível em: <http://www.planalto.gov.br/ccivil_03/LEIS/L0601-1850.htm>. Acesso em: 06 mar. 2015.

Lei 5.869 de 11 de janeiro de 1973. Institui o Código de Processo Civil. Diário Oficial da República Federativa do Brasil, Brasília, DF, 17 jan. 1973. Disponível em: <http://www.planalto.gov.br/ccivil_03/leis/L5869.htm>. Acesso em: 03 set. 2015.

Lei no 13.105 de 16 de março de 2015. Código de Processo Civil. Diário Oficial da República Federativa do Brasil, Brasília, DF, 17 mar. 2015. Disponível em: <http://www.planalto.gov.br/ccivil_03/_Ato2015-2018/2015/Lei/L13105.htm>. Acesso em: 05 out. 2015.

CHAUÍ, Marilena. A Sociedade Democrática. In: Introdução ao Direito Agrário. Curso de Extensão Universitária, Série O Direito Achado na Rua. v.3. Brasília: Editora UnB, pp. 333-339, 2002.

CHAUÍ, Marilena et al. Desordem e Processo: Estudos sobre o Direito em Homenagem a Roberto Lyra Filho. 1aed. Porto Alegre: Fabris Editor, 1986.

ENGELS, Friedrich. Sobre a Questão da Moradia. 1aeed. São Paulo: Boitempo, 2015.

ENGELS, Friedrich; MARX, Karl. Manifesto Comunista. 1aed. São Paulo: Boitempo, 2010. 
FAORO, Raymundo. Os Donos do Poder: Formação do patronato político brasileiro. 3a ed. São Paulo: Globo, 2001.

GORENDER, Jacob. A Escravidão Reabilitada. São Paulo: Ática, 1990.

KAREPOVS, Dainis. A Classe Operária vai ao Parlamento. 1aed. São Paulo: Alameda, 2006.

LIMA, Ruy Cirne. Pequena História Territorial do Brasil. Sesmarias e Terras Devolutas. 2aed. Porto Alegre: Livraria Sulina, 1954.

LYRA FILHO, Roberto. O que é Direito. 17ạed. São Paulo: Brasiliense, 1982.

MARÉS, Carlos Frederico. A Função Social da Terra. 1aed. Porto Alegre: Sergio Antonio Fabris Editor, 2003.

MARTINS, José de Souza. Os Camponeses e a Política no Brasil. 2ª ed. Petrópolis: Vozes, 1983. O Cativeiro da Terra. 9ạed. São Paulo: Contexto, 2010.

O Poder do Atraso. Ensaios de Sociologia da História Lenta. 1ạed. São Paulo: Hucitec, 1994.

PACHUKANIS, E.B. Teoria Geral do Direito e Marxismo. 1aed. São Paulo: Acadêmica, 1988.

SANTOS, Boaventura de Sousa. O Estado, o Direito e a Questão Urbana. Revista Crítica de Ciências Sociais, São Paulo, n.9, p. 9-86, jun. 1982.

SOARES, Moisés Alves; PAZELLO, Ricardo Prestes. Direito e Marxismo: Entre o Antinormativo e o Insurgente. Disponível em: <http://www.epublicacoes.uerj.br/index.php/revistaceaju/article/viewFile/13109/10656>. Acesso em: 10 ago. 2015.

STUTCHKA, Piotr. Direito de Classe e Revolução Socialista. 1aed. São Paulo: Instituto José Luís e Rosa Sundermann, 2001. 
Revista de Direito da Cidade

vol. 10, no 4. ISSN 2317-7721

DOI: $10.12957 /$ rdc. 2018.34476

Trabalho enviado em 28 de maio de 2018

Aceito em 08 de agosto de 2018 